\title{
INTRODUCTION OF CRATAEGUS L. SAMPLES IN THE KOLA NORTH
}

(C) 2017

Goncharova Oksana Aleksandrovna, candidate of biological sciences, senior researcher of Plant Introduction and Acclimatization Laboratory

Poloskova Elena Yurievna, candidate of biological sciences, deputy director for science Zotova Olesya Evgenievna, junior researcher of Plant Introduction and Acclimatization Laboratory Lipponen Irina Nikolaevna, leading engineer of Plant Introduction and Acclimatization Laboratory Polar-Alpine Botanical Garden-Institute of the Kola Science Center RAS (Apatity, Murmansk Region, Russian Federation)

Abstract. The paper deals with the introduction of genus Crataegus L. samples in Polar-Alpine Botanical GardenInstitute. The paper presents long-term periods of phenological phases onset of 14 Crataegus L. samples. Features of generative phenological development of 11 Crataegus L. samples are described. In the introduced Crataegus L. plants the time for the phenological phases passage depends on the origin and age. Adaptive advantages are plants of natural origin. This category of samples record phenophases of linear growth and lignifications of annual shoots which favorably affects the degree of adaptation. The phenophases onset of the majority of plants of the older and younger age groups is noted at close time. In plants of the older age group the phases of linear growth end and shoots' lignifications are marked earlier than those of 18-19-year-olds. The indicators characterizing generative development (the duration of the prefloral period, flowering) are appropriate when assessing the adaptability of introduced plants. The majority of the samples are characterized by regular flowering and fruiting. The studied plants belong to the group with the average flowering onset. Short prefloral period contributes to early start and flowering end, earlier ripening of.

Keywords: introduction; phenological development; phenological phases; vegetation duration; woody plants; collection funds; Rosaceae Juss.; family Rosaceous; genus Crataegus L. - hawthorn; generative development; prefloral period; bloom duration; Kola Subarctic.

УДК 504.062.2 /502.63

\section{ОПРЕДЕЛЕНИЕ ОСОБЕННОСТЕЙ СОЗДАНИЯ ОПТИМАЛЬНОЙ СТРУКТУРЫ АГРОЛАНДШАФТОВ ОРЕНБУРГСКОЙ ОБЛАСТИ}

(C) 2017

\author{
Евстифеева Татьяна Александровна, кандидат сельскохозяйственных наук, \\ доцент кафедры экологии и природопользования \\ Глуховская Марина Юрьевна, кандидат технических наук, \\ доцент кафедры экологии и природопользования \\ Оренбургский государственный университет (2. Оренбург, Российская Федерация)
}

Аннотащия. В данной статье определяется степень антропогенной преобразованности территории отдельного региона с преобладанием земель сельскохозяйственного назначения. В Оренбургской области, где в ряде административных районов распаханность достигает более трети территории, что в целом снижает ее экологическую стабильность, необходимость такого рода исследований очевидна.

Проводится анализ категориального распределения земельного фонда. Выявлены временные изменения площади отдельных категорий и определена степень антропогенной преобразованности по коэффициенту земельного использования, коэффициенту, учитывающему интенсивность использования сельхозугодий и коэффициенту распаханности, который отражает удельный вес пашни в составе сельскохозяйственных земель.

Выявлен ряд несоответствий по предельно допустимым и оптимальным экологическим параметрам: значительная площадь земель сельскохозяйственного фонда (88,5\% при норме для степных зон $60-65 \%$ и оптимуме 40\%), высокий уровень распаханности (более 50\% при норме 40-45\%), крайне низкая доля земель лесного фонда $(5,16 \%$ при норме $10-15 \%$ и оптимуме $15-20 \%)$ и в целом недостаток природных систем в составе земельных угодий (ООПТ 0,19-0,64\%).

Проведенные исследования свидетельствуют об интенсивном развитии агроландшафтов на территории области и необходимости искусственного поддержания равновесного состояния агроэкосистем, которое может достигаться только совокупностью мелиоративных, агрономических и экологических мероприятий.

Ключевые слова: земельный фонд; структура земельного фонда; антропогенная преобразованность; коэффициент земельного использования; коэффициент распаханности; коэффициент интенсивности использования сельхозугодий; экологическая нагрузка; предельно-допустимые экологические нагрузки; Оренбургская область.

Оренбургская область относится к регионам Российской Федерации с очень обширной территорией ( 29 место по площади среди 85 субъектов), включает 4,9\% площади всех российских сельхозугодий, явля- ясь при этом одним из крупнейших в России поставщиков сельскохозяйственной продукции, прежде всего зерновых культур, ежегодный урожай которых составляет в среднем около 2,5 млн тонн. 
Структура земельного фонда области обусловливает необходимость расширения инструментария мониторинговых исследований территорий, созданных человеком и развивающихся в дальнейшем по естественным законам устойчивости природных систем, с целью проектирования, внедрения и эксплуатации более эффективных и щадящих для биоты, геологической среды таких значимых для народного хозяйства и благополучия человека объектов, как сельскохозяйственные угодья, искусственные водоемы, лесополосы и лесопарки, рекреационные объекты и другие природно-антропогенные комплексы.

В процессе освоения и использования новых земель наибольшие негативные изменения, в отличие от других категорий, претерпевают земли населенных пунктов, промышленности (их вклад в общую площадь территории области в сумме составляет не более $3,5 \%$ ) и земли сельскохозяйственного назначения [1-5].

По данным национальных докладов о состоянии и использовании земель в Российской Федерации и государственных докладов о состоянии и об охране окружающей среды Оренбургской области [6], была проанализирована структура земельного фонда исследуемого региона за период с 1992 по 2015 гг. В
Оренбуржье земли сельскохозяйственного назначения занимают в среднем $88,5 \%$ от общей площади территории, что свидетельствует о доминировании аграрного сектора в экономике, отличающегося высоким уровнем антропогенной нагрузки на почвы. В составе земель сельскохозяйственного назначения выделяются собственно сельскохозяйственные угодья, а также другие земли, занятые внутрихозяйственными дорогами, хозяйственными зданиями, строениями и сооружениями, коммуникациями и т.д. [7]. Сравнительный анализ структуры земель относительно устойчивых территорий, к которым относят ненарушенные или слабонарушенные земли с предельно допустимыми и оптимальными экологическими параметрами за период с 1992 года по 2015 год, позволяет сделать ряд выводов. Несмотря на то, что доля лесных площадей с 1992 года увеличилась с 4,27\% до 5,16\%, этот показатель значительно ниже предельно допустимых экологических параметров (норма для степных зон не менее 10\% $15 \%$, а оптимальный интервал от $15 \%$ до $20 \%$ ), площадь ООПТ увеличилась на $355,5 \%$, но на настоящий момент составляет $0,64 \%$, при среднем значении этого показателя по России - 7\% (табл. 1).

таблица 1 - Доля площади земель по категориям [6]

\begin{tabular}{|c|c|c|c|c|c|c|}
\hline Года & $\begin{array}{c}\text { Доля с/х земель } \\
\text { от общей } \\
\text { площади } \\
\end{array}$ & $\begin{array}{c}\text { Доля пашни в } \\
\text { общей площа- } \\
\text { ди земель } \\
\end{array}$ & $\begin{array}{c}\text { Доля кормовых } \\
\text { угодий от пло- } \\
\text { щади с/х угодий }\end{array}$ & $\begin{array}{c}\text { Доля лесных } \\
\text { площадей от } \\
\text { общей площади }\end{array}$ & $\begin{array}{c}\text { Доля ООПТ } \\
\text { в общей } \\
\text { площади } \\
\end{array}$ & $\begin{array}{c}\text { Доля селитебных } \\
\text { территорий в } \\
\text { общей площади }\end{array}$ \\
\hline 1992 & $86,94 \%$ & $56,59 \%$ & $39,83 \%$ & $4,27 \%$ & $0,18 \%$ & $6,14 \%$ \\
\hline 1993 & $86,13 \%$ & $57,06 \%$ & $40,09 \%$ & $4,26 \%$ & $0,18 \%$ & $6,99 \%$ \\
\hline 1994 & $85,06 \%$ & $57,69 \%$ & $40,61 \%$ & $4,27 \%$ & $0,19 \%$ & $8,06 \%$ \\
\hline 1995 & $84,67 \%$ & $57,95 \%$ & $40,35 \%$ & $4,26 \%$ & $0,19 \%$ & $8,43 \%$ \\
\hline 1996 & $84,39 \%$ & $58,06 \%$ & $40,50 \%$ & $4,28 \%$ & $0,19 \%$ & $8,43 \%$ \\
\hline 1997 & $83,56 \%$ & $58,60 \%$ & $40,94 \%$ & $4,31 \%$ & $0,19 \%$ & $9,05 \%$ \\
\hline 1998 & $88,31 \%$ & $56,34 \%$ & $42,77 \%$ & $5,40 \%$ & $0,19 \%$ & $2,86 \%$ \\
\hline 1999 & $88,40 \%$ & $56,22 \%$ & $42,76 \%$ & $5,40 \%$ & $0,19 \%$ & $2,85 \%$ \\
\hline 2000 & $88,33 \%$ & $56,20 \%$ & $42,84 \%$ & $5,40 \%$ & $0,19 \%$ & $2,89 \%$ \\
\hline 2001 & $88,20 \%$ & $56,28 \%$ & $42,86 \%$ & $5,40 \%$ & $0,19 \%$ & $3,22 \%$ \\
\hline 2002 & $88,63 \%$ & $55,98 \%$ & $42,65 \%$ & $5,40 \%$ & $0,19 \%$ & $3,25 \%$ \\
\hline 2003 & $88,62 \%$ & $55,95 \%$ & $42,69 \%$ & $5,41 \%$ & $0,19 \%$ & $3,25 \%$ \\
\hline 2004 & $88,62 \%$ & $55,94 \%$ & $42,69 \%$ & $5,41 \%$ & $0,19 \%$ & $3,24 \%$ \\
\hline 2005 & $88,62 \%$ & $55,94 \%$ & $42,73 \%$ & $5,41 \%$ & $0,19 \%$ & $3,23 \%$ \\
\hline 2006 & $88,62 \%$ & $55,94 \%$ & $42,73 \%$ & $5,41 \%$ & $0,19 \%$ & $3,23 \%$ \\
\hline 2007 & $88,64 \%$ & $55,93 \%$ & $42,71 \%$ & $5,41 \%$ & $0,19 \%$ & $3,25 \%$ \\
\hline 2008 & $88,50 \%$ & $55,87 \%$ & $42,82 \%$ & $5,51 \%$ & $0,19 \%$ & $3,26 \%$ \\
\hline 2009 & $88,48 \%$ & $55,89 \%$ & $42,77 \%$ & $5,51 \%$ & $0,19 \%$ & $3,27 \%$ \\
\hline 2010 & $88,43 \%$ & $55,93 \%$ & $42,79 \%$ & $5,11 \%$ & $0,64 \%$ & $3,27 \%$ \\
\hline 2011 & $88,42 \%$ & $55,94 \%$ & $42,78 \%$ & $5,11 \%$ & $0,64 \%$ & $3,27 \%$ \\
\hline 2012 & $88,36 \%$ & $55,96 \%$ & $42,80 \%$ & $5,16 \%$ & $0,64 \%$ & $3,28 \%$ \\
\hline 2013 & $88,36 \%$ & $55,95 \%$ & $42,81 \%$ & $5,16 \%$ & $0,64 \%$ & $3,28 \%$ \\
\hline 2014 & $88,36 \%$ & $55,96 \%$ & $42,81 \%$ & $5,16 \%$ & $0,64 \%$ & $3,28 \%$ \\
\hline 2015 & $88,36 \%$ & $55,96 \%$ & $42,81 \%$ & $5,16 \%$ & $0,64 \%$ & $3,28 \%$ \\
\hline \multicolumn{7}{|c|}{ Нормативное значение экологических параметров } \\
\hline \multicolumn{7}{|c|}{ Предельно допустимый } \\
\hline & $65-60 \%$ & менее $60 \%$ & более $30 \%$ & $10-15 \%$ & $\begin{array}{c}\text { Средний } \\
\text { показатель } \\
\text { по РФ - 7\% } \\
\end{array}$ & менее $10 \%$ \\
\hline \multicolumn{7}{|c|}{ Оптимальный } \\
\hline & не более $40 \%$ & $40-45 \%$ & $40-50 \%$ & $15-20 \%$ & $\begin{array}{c}\text { Средний } \\
\text { показатель } \\
\text { по РФ - 7\% }\end{array}$ & $1-3 \%$ \\
\hline
\end{tabular}


Длительное выращивание сельскохозяйственных культур на одной и той же площади приводит к значимым изменениям в состоянии почвенного покрова. Земледелие доиндустриального периода обеспечивало повышение биологической активности почв, о чем свидетельствовало увеличение скорости размножения микроорганизмов, процессов гумусообразования [8]. Тогда как современная культура земледелия (в том числе в процессе массового освоения целинных зе- мель) приводит к потере традиционной структуры почв, к уменьшению в них содержания гумуса с заметным снижением почвенного плодородия.

Таким образом, наибольший вклад в показатель антропогенной преобразованности по причине максимальной площади вносят земли сельскохозяйственного назначения. На рис. 1 представлена динамика изменения площади сельскохозяйственных земель за 23 года (период с 1992 по 2015 гг.).

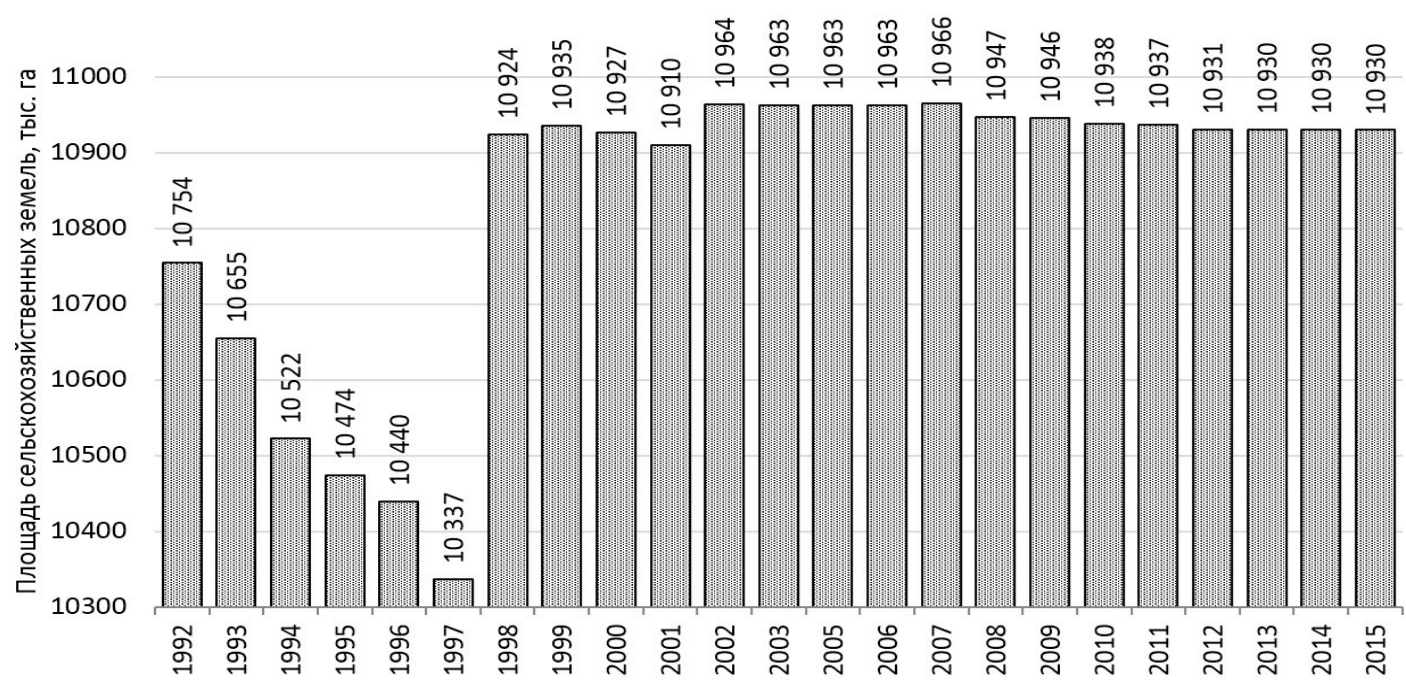

Рисунок 1 - Изменение площади сельскохозяйственных земель [6]

Для оценки степени преобразованности региональных территорий с преобладанием земель сельскохозяйственного назначения, наряду с широко применяемыми исследованиями структуры земельного фонда [9-16], целесообразно также производить учет таких показателей, как:

- степень сельскохозяйственной освоенности земель;

- степень распашки;

- интенсивность использования угодий и т.п.

С этой целью производится расчет следующих коэффициентов:

- интенсивность использования сельскохозяйственных угодий (Кинт);

- использование земельных ресурсов (КЗИ);

- распаханность (Красп).

КЗИ - коэффициент земельного использования. Позволяет оценить степень использования земельных угодий собственно в процессах, напрямую связанных с сельскохозяйственным производством.

Коэффициент определяется по формуле:

$$
\text { КЗИ }=\frac{S c . x}{S_{0}},
$$

где $\mathrm{So}$ - общая площадь, га; $\mathrm{Sc} / \mathrm{x}$ - площадь сельскохозяйственных угодий, га.

Кинт - коэффициент, учитывающий интенсивность использования сельскохозяйственных угодий (процент используемых земель от общей площади сельхозугодий). Определяется по формуле:

$$
\text { Кинт }=\frac{\sum \text { Sи.у. }}{S c / \mathrm{x}},
$$

где $\sum$ Sи. у - площади улучшенных пастбищ, пашни, га.

Улучшение экологической обстановки на территории сельскохозяйственных угодий напрямую зависит от снижения интенсивности их использования.
Красп - данный коэффициент (распаханности) отражает удельный вес пашни в составе сельскохозяйственных угодий. Рассчитывается по формуле:

$$
\text { Красп }=\frac{S \Pi}{S c / x},
$$

где Sп - площадь пашни, га.

Результаты произведенных расчетов за весь исследуемый период представлены в табл. 2.

Графическое отображение динамики площади сельскохозяйственных угодий и степени интенсивности их использования с момента стабилизации их площадей и окончательного закрепления за отдельными категориями землепользования представлена на рис. 2 и 3.

Анализ полученных результатов свидетельствует о том, что, несмотря на незначительные колебания по годам такого параметра, как, например, площадь распаханных сельскохозяйственных земель за весь период, этот показатель не опускался ниже 50\%, тогда как, согласно результатам исследований Н.Ф. Реймерса (1990 г., 1994 г.), В.Е. Синешкова, А.И. Южакова (2005 г.), для сохранения оптимальных экологических параметров сбалансированной территориальной организации в степной зоне доля распаханных земель не должна превышать 40-45\%, а доля естественных территорий (неосвоенных) должна составлять 40-60\%.

Наряду с распаханностью территории к важнейшим критериям оценки техногенной преобразованности земель сельскохозяйственного назначения относится коэффициент их использования, который в нашей области чрезвычайно высок, то есть практически вся площадь сельхозугодий используется либо в качестве пашни, либо для выпаса скота.

Постоянное изъятие урожая, интенсивное вмешательство в процессы почвообразования, длительное 
Евстифеева Т.А., Глуховская М.Ю.

Определение особенностей создания оптимальной структуры...

03.02.00 - общая биология

выращивание монокультур на сельскохозяйственных землях неизбежно приводит к снижению плодородия почв (закон убывающего плодородия), к тому же, агроэкосистемы относятся к крайне неустойчивым биоценозам, так как не способны саморегулироваться и самовосстанавливаться. Искусственные экосистемы отличает резкое снижение биологического многообразия.

Таблица 2 - Коэффициенты интенсивности использования сельскохозяйственных угодий

\begin{tabular}{|c|c|c|c|}
\hline Года & КЗИ & Кинт & Красп \\
\hline 1992 & 0,869363 & 0,964209 & 0,565937 \\
\hline 1993 & 0,861312 & 0,971430 & 0,570552 \\
\hline 1994 & 0,850593 & 0,983036 & 0,579483 \\
\hline 1995 & 0,846712 & 0,983015 & 0,580576 \\
\hline 1996 & 0,843948 & 0,985584 & 0,585957 \\
\hline 1997 & 0,835605 & 0,995318 & 0,563379 \\
\hline 1998 & 0,883082 & 0,991102 & 0,562225 \\
\hline 1999 & 0,884003 & 0,989776 & 0,56201 \\
\hline 2000 & 0,883349 & 0,990428 & 0,562812 \\
\hline 2001 & 0,881991 & 0,99143 & 0,559821 \\
\hline 2002 & 0,886283 & 0,986364 & 0,559500 \\
\hline 2003 & 0,886243 & 0,986445 & 0,559382 \\
\hline 2004 & 0,886243 & 0,986318 & 0,559387 \\
\hline 2005 & 0,886235 & 0,986655 & 0,559402 \\
\hline 2006 & 0,886210 & 0,986682 & 0,559272 \\
\hline 2007 & 0,886445 & 0,986385 & 0,558700 \\
\hline 2009 & 0,884965 & 0,986892 & 0,558905 \\
\hline 2010 & 0,884828 & 0,986625 & 0,559296 \\
\hline 2011 & 0,884254 & 0,987192 & 0,559398 \\
\hline 2012 & 0,884165 & 0,987191 & 0,559640 \\
\hline 2013 & 0,883624 & 0,987668 & 0,559545 \\
\hline 2015 & 0,883599 & 0,987667 & 0,559552 \\
\hline & 0,883575 & 0,987658 & 0,559542 \\
\hline
\end{tabular}

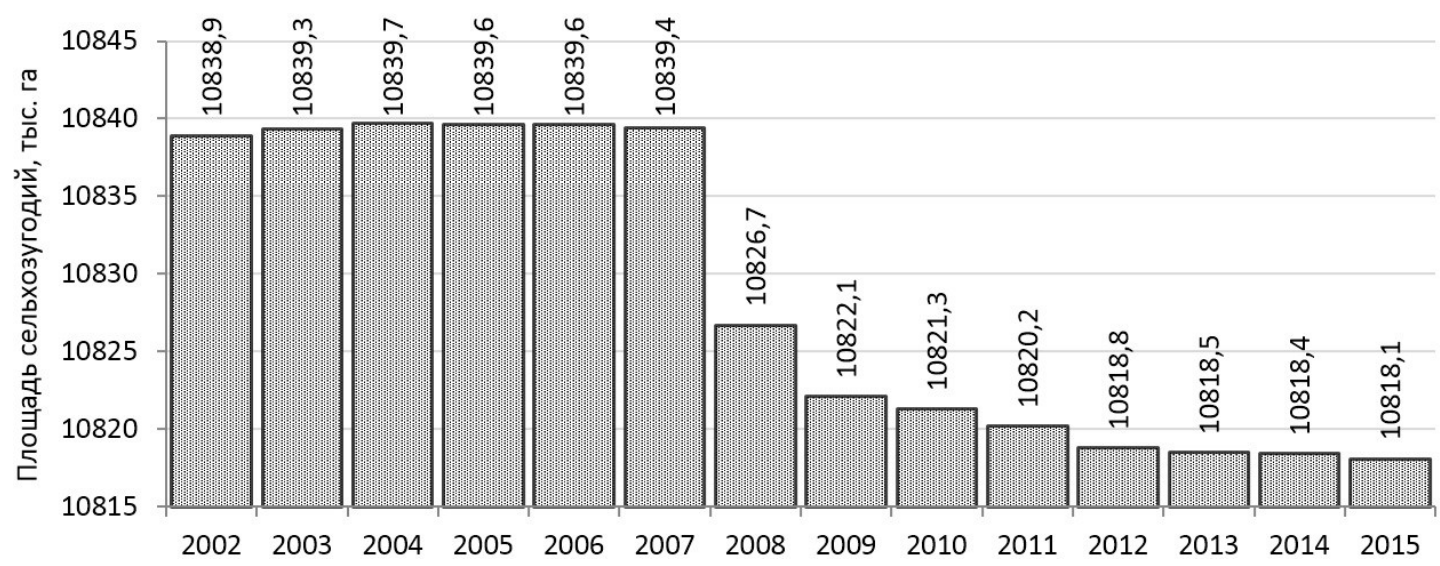

Рисунок 2 - Динамика общей площади сельскохозяйственных угодий в Оренбургской области за период с 2002 по 2015 гг. [6]

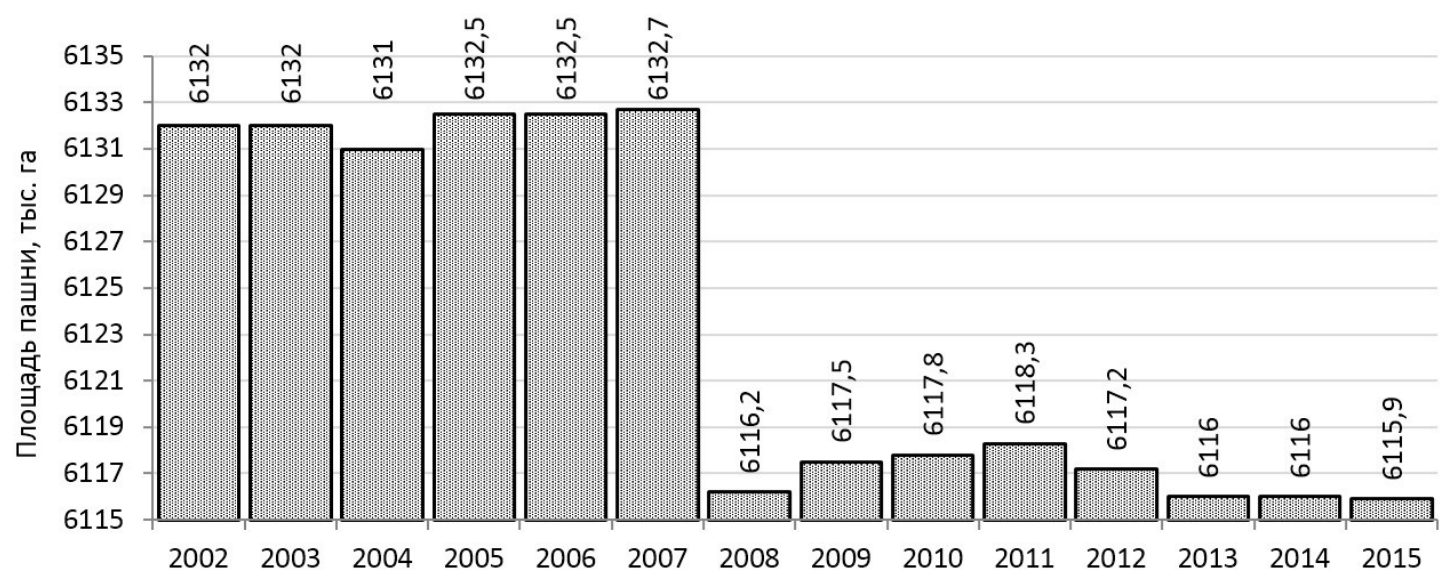

Рисунок 3 - Динамика площади пашни в Оренбургской области за период с 2002 по 2015 гг. [6] 
Неблагоприятная экологическая ситуация усугубляется тем, что 4/5 площади области пашни находится в степной и сухостепной зонах, что связано с систематическим недостатком влаги и высокой интенсивностью эрозионных процессов [17].

С точки зрения экологической целесообразности крайне опасно производить упрощение природного окружения человека путем превращения большей части естественных экосистем в агроэкосистемы. Поэтому основная стратегия дальнейшего развития высокопродуктивных и устойчивых ландшафтов должна заключаться в сохранении естественных экосистем и умножении их многообразия.

Таким образом, интенсивное развитие агроэкосистем на территории области привело к необходимости искусственного поддержания равновесного состояния, которое достигается реализацией системы мелиоративных, агрономических и экологических мероприятий, которая должна включать:

- снижения площади пашни, как минимум, до $60 \%$ от общей площади сельскохозяйственных угодий (перевод в сенокосно-пастбищные угодья, вывод из хозяйственного использования);

- увеличения доли площади лесозащитных полос на распаханных территориях до 5-7\% с целью защиты от всех видов эрозии почв;

- организации степных резерватов (зон покоя), занимающих до $12 \%$ от общей площади пастбищных угодий;

- развитие сети степных ООПТ.

Bce вышеперечисленное позволит сбалансировать территориальную организацию региона и сохранить типичную структуру, характерную для степных экосистем.

\section{СПИСОК ЛИТЕРАТУРЫ:}

1. Айдаров И.П. Обустройство агроландшафтов России. М.: МГУП, 2007. 312 с.

2. Bucek A. Ecological stability and ecological stress in environmental geography [Ekologicka stabilita a ekologicky stres v geografii zivotniho prostredi]: Sbornik Praci - 1988. CSAV 18. P. 69-75.

3. Bucek A., Ungerman J. Complete land reformations in the territory of the productional-organisational unit Merin and agricultural utilization of the landscape. [Souhrnne pozemkove upravy na uzemi vyrobne organizacni jednotky Merin a zemedelske vyuzitikrajiny]: Zpravy Geografickeho - Ustavu Csav. 1978. 15 (6-7). P. 93-104.

4. Buček A., Lacina J. Supraregional territorial system of landscape-ecological stability of the former
Czechoslovakia: Ekologia Bratislava. 1996. 15 (1). P. 71-76.

5. Masný M., Zaušková L. Multi-temporal analysis of an agricultural landscape transformation and abandonment (Lubietová, Central Slovakia): Open Geosciences. 2015. 7 (1). Р. 888-896.

6. Государственный доклад «О состоянии и об охране окружающей среды Оренбургской области» / Под общей редакцией министра природных ресурсов, экологии и имущественных отношений Оренбургской области. 1992-2015 гг.

7. Земельный Кодекс Российской Федерации от 25 октября 2001 г. № 136-Ф3. Ст. 77: [в ред. от 03.07.2016 г.] // Собрание законодательства Российской Федерации. 2001. № 44. С. 4147.

8. Чибилев А.А. Географический атлас Оренбургской области. Оренбург: Оренбургское книжное издательство, 1999. 95 с.

9. Глуховская М.Ю., Евстифеева Т.А. Анализ устойчивости региональных территорий (на примере отдельного района Оренбургской области) // Материалы всерос. науч.-метод. конф. 2016. С. 779-785.

10. Глуховская М.Ю. Анализ экологической устойчивости и стабильности региональной территории на примере Оренбургской области // Вестник ОГУ. 2017. № 4. С. 53-60.

11. Moyzeova M., Kenderessy P. Territorial systems of ecological stability in land consolidation projects (example of proposal for the lses of klasov village, slovak republic): Ekologia Bratislava. 2015. 34 (4). P. 356-370.

12. Jurko A. Übersicht über die pflanzengesellschaften des cynosurion-verbandes in den karpaten: Vegetatio. 1969. Vol. 18. Issue 1. P. 222-223.

13. Jurko A., Peciar V. Pflanzengesellschaften an schattigen felse en westkarpaten: Vegetatio Acta Geobotanica. 1963. Vol. 11. Issue 4. P. 199-209.

14. Voloscuk I. Ecological stability in the Tatra mountains forests: Ekologia Bratislava 1998. 17(1). P. 3948 .

15. Zaušková L. Landscape-ecological interpretation and applications of landscape survey results for optimal land use: Ekologia Bratislava. 2014. 33 (3). P. 252-258.

16. Supuka J., Uhrin P. Share of scattered woody vegetation in landscape ecological stability and agriculture sustainability: Folia Oecologica. 2016. 43 (2), P. 193-203.

17. Блохин Е.В. Экология почв Оренбургской области: почвенные ресурсы, мониторинг, агроэкологическое районирование. Екатеринбург: УрОРАН, 1997. 228 с.

\title{
PECULIARITIES OF OPTIMAL STRUCTURE OF ORENBURG REGION AGROLANDSCAPES
}

(C) 2017

\author{
Evstifeeva Tatyana Aleksandrovna, candidate of agricultural sciences, \\ associate professor of Ecology and Nature Management Department \\ Glukhovskaya Marina Yuryevna, candidate of technical sciences, \\ associate professor of Ecology and Nature Management Department \\ Orenburg State University (Orenburg, Russian Federation)
}

Abstract. In this article the examines the degree of change of regional territories is examined with predominance of earth of the agricultural setting. In the Orenburg Region where in a number of administrative regions more than one third of the territory is plowed, necessity such the researches obvious.

The analysis of the distribution of the land fund by category is carried out. Time changes in all land categories were studied, and the level of anthropogenic transformation was determined by the coefficient of land use, the coefficient that takes into account the intensity of agricultural land use and the coefficient of plowing of agricultural lands. 
A number of disproportions are formed in accordance with the maximum possible and optimal environmental parameters: a large agro-land plot (88,5\%, with a norm for steppe zones of $60-65 \%$ and an optimal $40 \%$ ), a lot of arable land (more than 50\%, 40-45\%), an extremely low proportion of forest land $(5,16 \%$ in $10-15 \%$ and the optimal value of $15-20 \%$ ), as well as a general lack of natural lands (OOP $0,19-0,64 \%$ ).

Undertaken studies testify to intensive development of agrolandscapes on territory of area, and necessity of artificial maintenance of the equilibrium state of agroecosystems, that can be arrived at only by totality of reclamative, agronomical and ecological events.

Keywords: landed fund; structure of landed fund; anthropogenic преобразованность; соefficient of landed use; coefficient of thrown open; maximum-possible ecological loading; Orenburg area.

УДК $581.4+581.9+582+615$

\section{ТАКСОНОМИЧЕСКАЯ И ЭКОЛОГИЧЕСКАЯ СТРУКТУРА «СОРНЫХ» ЛЕКАРСТВЕННЫХ РАСТЕНИЙ ТЕРРИТОРИИ БИОСФЕРНОГО РЕЗЕРВАТА «ПРИБУЖСКОЕ ПОЛЕСЬЕ»}

(C) 2017
Зеркаль Сергей Владимирович, кандидат биологических наук, доцент кафедры ботаники и экологии
Бондарь Юлия Владимировна, старший преподаватель кафедры ботаники и экологии
Домась Андрей Степанович, кандидат сельскохозяйственных наук, старший преподаватель кафедры ботаники и экологии
Брестский государственный университет имени А.С. Пушкина (2. Брест, Республика Беларусь)

Аннотация. В данной статье рассматривается аспекты систематической и экологической структуры «сорных» лекарственных растений, произрастающих на территории биосферного резервата «Прибужское Полесье». Сорные представители исследуемого региона являются перспективными видами для применения их в фармакологии и медицине. Поэтому детальное изучение экологических групп и хозяйственное значение синантропных лекарственных растений могут послужить основой для развития новых тенденций в ресурсоведении лекарственных растений. В работе определены диагностические признаки, а также сходства и различия морфометрических показаний. Сбор полевого материала производился методом рекогносцировки местности. Проведенные исследования показывают, что территория биосферного резервата «Прибужское Полесье» характеризуется богатым видовым составом синантропных «сорных» лекарственных растений 57 видов, произрастающих в различных местообитаниях, которые можно применять при лечении болезней желудочно-кишечного тракта, системы кровообращения и органов дыхания. Результаты исследования говорят о том, что синантропные виды лекарственных растений можно широко применять при лечении тех или иных заболеваний. «Сорные» лекарственные растения нужно и можно вовлекать в оборот в лекарственных целях для увеличения ресурсной базы получения биологически активных веществ растений.

Ключевые слова: видовой состав; многолетнее травянистое растение; мезофит; рекогносцировка местности; фармакологически активные вещества; биосферный резерват «Прибужское Полесье»; «сорные» лекарственные растения; систематическая и экологическая структура; ресурсоведение.

\section{Актуальность исследований}

В последние годы сырьевая база лекарственных растений резко сократилась в результате широкого их использования, а также вредных мероприятий хозяйственной деятельности человека. Но наряду с этим появилось много синантропных растений, которые сопутствуют хозяйственной деятельности человека. Их территория распространения становится все больше, и все чаще человек задумывается об их использовании в этой или иной области, а также в качестве лекарственного сырья. Выявление основных биологически активных веществ «сорных» лекарственных растений поможет выявить особенности их применения в фармакологии, медицине, а также заменить ими дорогостоящие препараты синтетического происхождения [1]. Вышесказанное и послужило побудительным мотивом для проведения наших исследований и определяет их актуальность.

\section{Новизна полученных результатов}

Впервые проведены детальные исследования синантропных растений, произрастающих на территории биосферного резервата «Прибужское Полесье»; собран гербарный материал, проведен географический и таксономический анализ видов.

\section{Научная и практическая значимость}

Полученные нами данные могут послужить основой для развития новых тенденций в ресурсоведении лекарственных растений, в медицине, фармакологии.

В 2002 г. в результате исследований ученых и специалистов Отдела проблем Полесья Национальной академии наук Беларуси, Брестского госуниверситета, УП «БелНИЦзем», Белорусского государственного университета было составлено обоснование объявления республиканского ландшафтного заказника «Прибужское Полесье». В декабре 2003 г. создан биосферный резерват «Прибужское Полесье», получивший в 2004 г. официальный статус биосферного резервата ЮНЕСКО [2].

Целью создания республиканского ландшафтного заказника «Прибужское Полесье» на территории Брестского района в Брестской области площадью 7,95 тысяч га является сохранение в естественном состоянии уникального природного ландшафта с популяциями редких и исчезающих видов растений и животных, охрана редких лесных биоценозов и геоморфологических образований на территории, занимающей важное место в международной сети особо охраняемых природных территорий, сохранение тра- 